\title{
Endoscopic retrograde appendicitis therapy: a novel approach for peri-appendiceal abscess
}

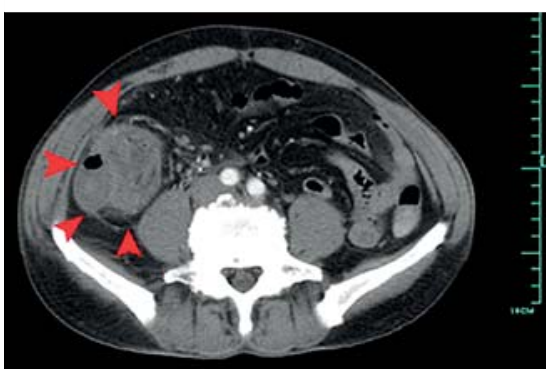

- Fig. 1 Abdominal contrast-enhanced computed tomography scan showing an irregular mass with a size of $5.5 \times 4.5 \mathrm{~cm}$ located in the ileocecal area (red arrowheads).
A 66-year-old man presented with recurrent abdominal pain for half a month. He wrongly thought it was acute gastritis, without initially paying any attention to it; however, as the pain became aggravating, he came to our hospital. An abdominal computed tomography (CT) scan revealed a peri-appendiceal abscess ( Fig.1). Endoscopic retrograde appendicitis therapy (ERAT) was then performed.

At colonoscopy, the cecum, including the ileocecal valve, was seen to be severely swollen and enlarged. A transparent cap fixed to the colonoscope was used to de- tect the appendiceal orifice. Milk-like pus was observed pouring out from the folded mucosa, which was presumed to be where the appendiceal orifice was situated. When this was successfully cannulated with an endoscopic retrograde cholangiopancreatography (ERCP) sphincterotome, a considerable quantity of pus poured out from the appendiceal cavity. The abscess cavity was shown on fluoroscopy to be $5.0 \times 4.5 \mathrm{~cm}$ in size. Irrigation with metronidazole was performed until the drainage fluid was clear. Finally, a $6-\mathrm{Fr} \times 6-\mathrm{cm}$ pancreatic stent was introduced into the appendiceal cavity over a
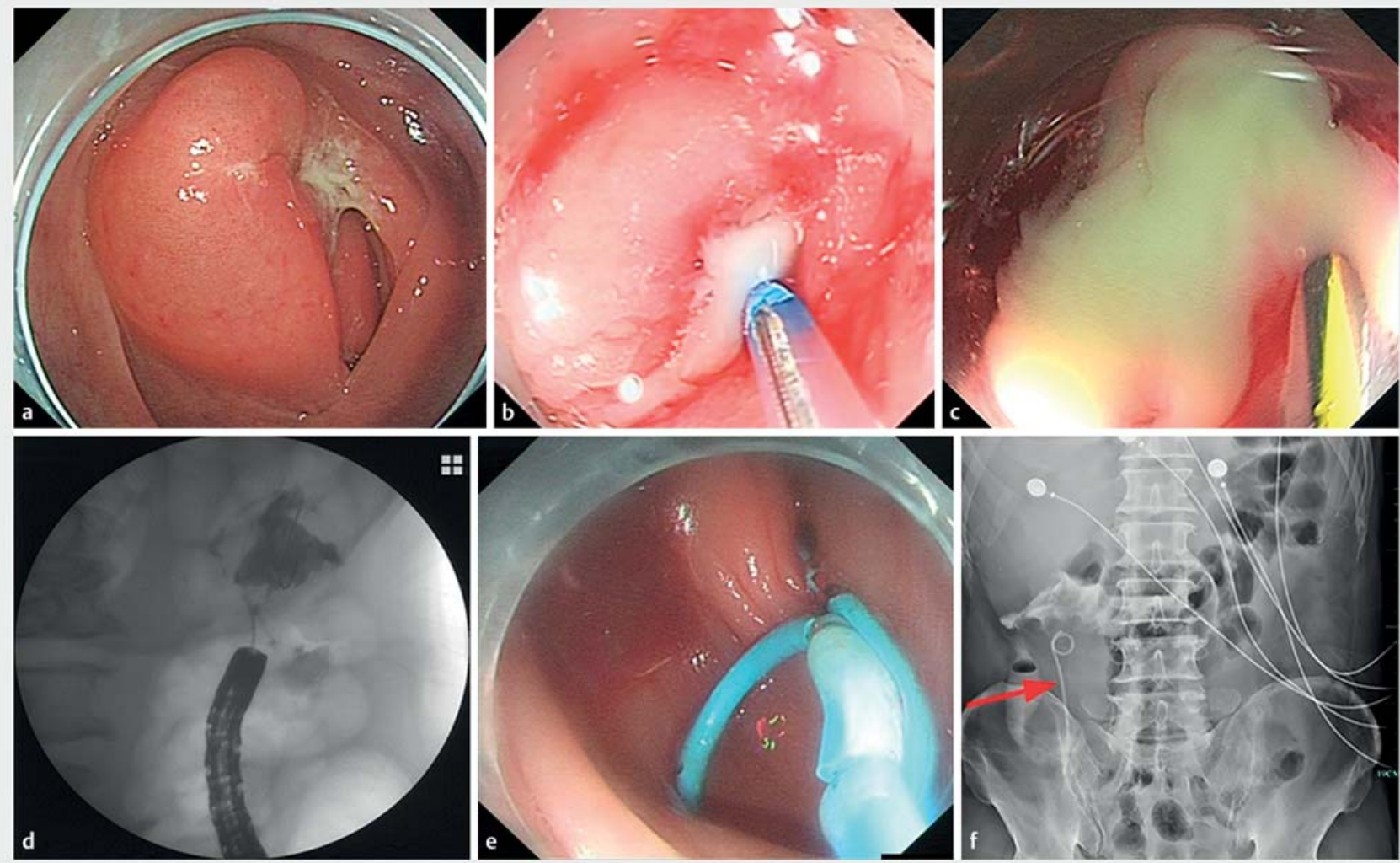

> Fig. 2 Images of endoscopic retrograde appendicitis therapy (ERAT) being performed in a patient with an appendiceal abscess showing: a severe swelling and enlargement of the cecum, including the ileocecal valve; $\mathbf{b}$ cannulation of the appendiceal orifice being performed with an endoscopic retrograde cholangiopancreatography sphincterotome; c pus flowing out, with decompression of the intra-appendiceal pressure; d the irregularly shaped cavity of the peri-appendiceal abscess $(5.0 \times 4.5 \mathrm{~cm}$ in size $)$ clearly displayed on fluoroscopy; e a $6-\mathrm{Fr} \times 6-\mathrm{cm}$ pancreatic stent that was placed into the appendiceal cavity over a guidewire to provide continuous drainage; $\mathbf{f}$ the correctly positioned stent on radiographic imaging. 


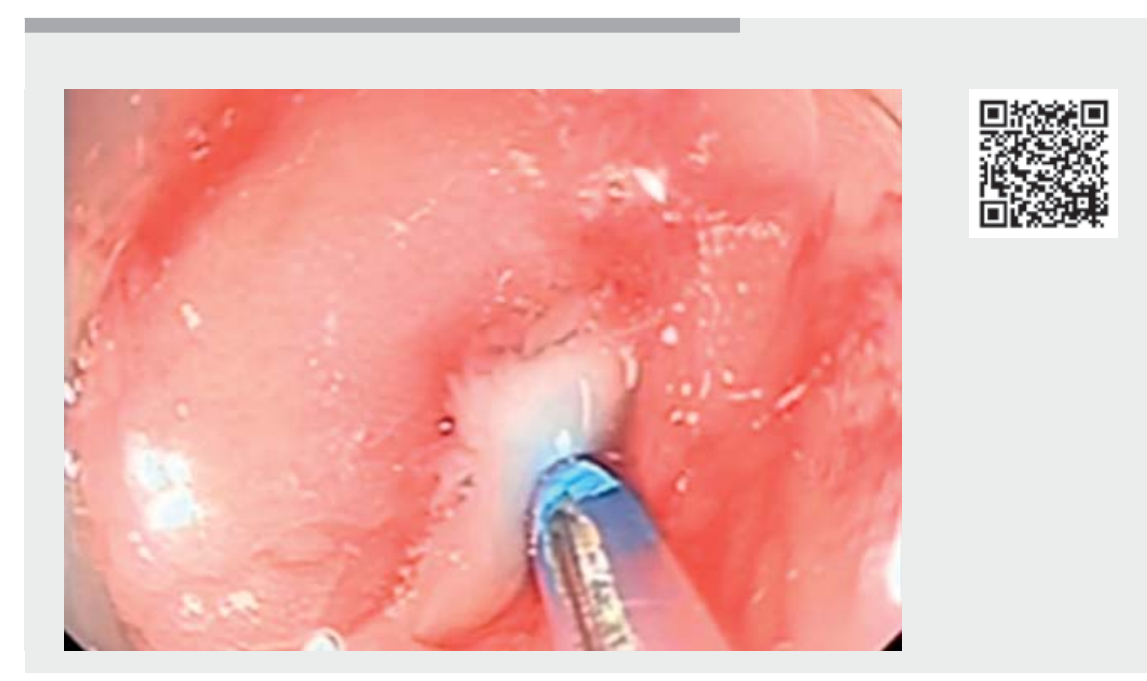

$\checkmark$ Video 1 Endoscopic drainage of a peri-appendiceal abscess with endoscopic retrograde appendicitis therapy (ERAT) in a 66-year-old man.

guidewire (>Fig. 2 ; > Video 1 ). The patient recovered uneventfully after the procedure.

A peri-appendiceal abscess is a condition of worsening acute appendicitis, with an incidence rate of approximately $4 \%-20 \%$ in patients with acute appendicitis [1]. Percutaneous drainage is recommended by the World Society of Emergency Surgery as the first-line treatment for the condition [2]. However, the minimally invasive procedure is also associated with several complications, such as bleeding, fistula formation, or injury to adjacent organs [1,2].

ERAT is an emerging technique that is used to manage acute appendicitis [3]. As experience has accumulated, we attempted to use ERAT to manage an appendiceal abscess. Between April 2020 and February 2021, nine patients with an appendiceal abscess underwent ERAT in our center. All of the patients had good outcomes, without the need for surgery. Within this small sample, ERAT seems to be promising in the treatment of appendiceal abscess; however, further research should be carried out.

Endoscopy_UCTN_Code_CPL_1AJ_2AF
Funding

Zhejiang Provincial Traditional Chinese Medicine Science and Technology Project 2020ZB153

Competing interests

The authors declare that they have no conflict of interest.

\section{The authors}

\section{Guangxing Cui ${ }^{1}$, Wen Lv' ${ }^{1}$, Jiahui Wang ${ }^{2}$, Xiaofeng Zhang ${ }^{1}$}

1 Department of Gastroenterology, Affiliated Hangzhou First People's Hospital, Zhejiang University School of Medicine, Hangzhou, China

2 Department of Gastroenterology, Fourth Clinical Medical College of Zhejiang Chinese Medical University, Hangzhou, China

\section{Corresponding author}

\section{Xiaofeng Zhang, MD, PhD}

Department of Gastroenterology, Affiliated Hangzhou First People's Hospital, Zhejiang University School of Medicine, No.261, Huan-sha Road, Hangzhou, China 18258855475@163.com

[1] Horn CB, Coleoglou Centeno AA, Guerra J] et al. Drain failure in intra-abdominal abscesses associated with appendicitis. Surg Infect 2018; 19: 321-325

[2] Di Saverio S, Podda M, De Simone B et al. Diagnosis and treatment of acute appendicitis: 2020 update of the WSES Jerusalem guidelines. World J Emerg Surg 2020; 15: 27

[3] Liu BR, Ma X, Feng J et al. Endoscopic retrograde appendicitis therapy (ERAT): a multicenter retrospective study in China. Surg Endosc 2015; 29: 905-909

Bibliography

Endoscopy 2022; 54: E186-E187

DOI $10.1055 / \mathrm{a}-1471-2871$

ISSN 0013-726X

published online 12.5.2021

(c) 2021. Thieme. All rights reserved. Georg Thieme Verlag KG, Rüdigerstraße 14, 70469 Stuttgart, Germany

\section{ENDOSCOPY E-VIDEOS}

https://eref.thieme.de/e-videos

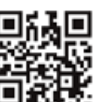

Endoscopy E-Videos is an open access online section, reporting on interesting cases and new techniques in gastroenterological endoscopy. All papers include a high quality video and all contributions are freely accessible online. Processing charges apply (currently EUR 375), discounts and wavers acc. to HINARI are available.

This section has its own submission website at

https://mc.manuscriptcentral.com/e-videos 